\title{
Análise da conformidade e percepção dos proprietários rurais dos projetos produtores de água
}

A Bacia Hidrográfica do Rio Camboriú (BHRC) abastece os municípios, Balneário Camboriú e Camboriú, a cada ano o recurso hídrico tem sido mais exigido, chegando a determinados períodos a estado crítico. A Agência Nacional de Águas (ANA) desenvolveu o Programa Produtor de Água (PPA) para colaborar na resolução do problema. Inspirado na ANA e experiências internacionais, foi criado o projeto Produtor de Água (PA) na BHRC, tendo como principal meta o aumento da quantidade e qualidade do recurso hídrico. O presente trabalho tem objetivo de avaliar a conformidade entre o PPA e PA, e medir a percepção dos proprietários rurais que aderiram ao PA. Na análise de conformidade foi identificado e mensurado o nível de consonância entre PPA e PA considerando, justificativa, descrição, objetivo geral e específicos, e metas. Na análise de percepção foi aplicado questionário avaliando o nível de satisfação. Os resultados mostram um nível de $90 \%$ de conformidade entre o PPA e PA. A percepção constatou alto grau de engajamento dos proprietários rurais no projeto PA, refletindo a confiança que demostram ter em relação ao mesmo. Os proprietários percebem que o projeto pode ser uma das soluções para resolver ou atenuar os efeitos da falta do recurso hídrico na BHRC. As análises de conformidade com o PPA e percepção dos proprietários rurais podem ser utilizadas como indicadoras de sucesso de projetos PA.

\section{Analysis of compliance and perception of rural owners of water- producing projects}

The Camboriú River Basin (BHRC) supplies the municipalities, Balneário Camboriú and Camboriú, each year the water resource has been more demanded, reaching certain periods in a critical state. The National Water Agency (ANA) has developed the Water Producer Program (PPA) to help solve the problem. Inspired by ANA and international experiences, the Water Producer (PA) project was created at BHRC, with the main goal being to increase the quantity and quality of the water resource. The present study aims to evaluate the conformity between the PPA and PA, and to measure the perception of the rural owners who joined the AP. The conformity analysis was identified and measured the level of consonance between PPA and AP considering, justification, description, general and specific objective, and goals. Regarding perception, a questionnaire was applied evaluating the level of satisfaction. The analysis showed $90 \%$ compliance between PPA and PA, the perception noted a high degree of engagement of rural landowners in the PA project, reflecting their confidence in the project. They realize that it can be one of the solutions to solve or mitigate the effects of the lack of water resources in the BHRC. Analyzes of conformity and perception of rural owners can be used as indicators of the PA projects success.

Keywords: Water Producer Project; Rural Owners; Water Management.

Topic: Desenvolvimento, Sustentabilidade e Meio Ambiente

Reviewed anonymously in the process of blind peer.
Received: $12 / 12 / 2019$

Approved: $19 / 02 / 2020$
Paulo Henrique Santos (iD)

Universidade do Vale do Itajaí, Brasil

http://lattes.cnpq.br/5454170480475253

http://orcid.org/0000-0002-3979-662X

santosph14@yahoo.com.br

Paulo Ricardo Schwingel

Universidade do Vale do Itajaí, Brasil

http://lattes.cnpq.br/5772922139047587

http://orcid.org/0000-0003-2524-9550

schwingel@univali.br
Referencing this:

SANTOS, P. H.; SCHWINGEL, P. R.. Análise da conformidade e percepção dos proprietários rurais dos projetos produtores de água. Nature and Conservation, v.13, n.1, p.32-42, 2020. DOI: http://doi.org/10.6008/CBPC2318-2881.2020.001.0005 


\section{INTRODUÇÃO}

O bioma Mata Atlântica é constituído por um conjunto de formações florestais e ecossistemas associados, os quais sofrem forte degradação ambiental no Brasil. Em sua extensão original, esse ambiente ocupava cerca de 150 milhões de hectares, sendo que fragmentos maiores que 100 hectares representam apenas 7,3\% da cobertura original (MMA, 2011). A proteção deste bioma é importante para a regularização dos recursos hídricos, pois comunidades tradicionais e populações rurais e urbanas dependem dos serviços ambientais que a Mata Atlântica proporciona, tanto no âmbito regional como global. Projeções indicam que as perdas no provimento de serviços ambientais afetarão diversos grupos humanos, principalmente para as populações mais pobres. Logo, a decisão de proteger esses ecossistemas e garantir o provimento de serviços ambientais é também uma escolha ética e de justiça social (MMA, 2011). A proteção dos serviços ambientais da Mata Atlântica depende da conservação de remanescentes de vegetação nativa, bem como da ampliação e fortalecimento de unidades de conservação e outras áreas protegidas. Além disso, são essenciais a promoção de práticas de uso da terra associadas com a proteção da biodiversidade para a conectividade ecológica entre fragmentos de habitats (MMA, 2012).

A qualidade e quantidade da água disponível estão relacionados com o crescimento demográfico. Dados do Fundo das Nações Unidas para a Infância e da Organização Mundial da Saúde, revelam que metade da população mundial não conta com serviço de saneamento básico (BARBOSA, 2015). A crescente urbanização e industrialização geram distintas fontes difusas de contaminação, comprometendo a qualidade dos recursos hídricos (TUNDISI et al., 2008). O Brasil tem o privilégio de possuir 12\% da reserva mundial de água doce (BICUDO et al., 2010), sendo fundamental usar este recurso de forma sustentável.

O Ministério do Meio Ambiente (MMA) criou a Agência Nacional de Águas (ANA), dedicada a fazer cumprir os objetivo e diretrizes da Lei das Água do Brasil, seguindo quatro linhas de ações, a saber: regulação, monitoramento, aplicação da lei e planejamento (ANA, 2018). A agência tem entre suas atribuições a de “propor ao Conselho Nacional de Recursos Hídricos o estabelecimento de incentivos, inclusive financeiros, à conservação qualitativa e quantitativa de recursos hídricos" (BRASIL, 2000), aos quais estão associados à conservação de solo e água. Nesse sentido, o Programa Produtor de Água (PPA) é uma ação que atende a todos esses dispositivos, pois, através da articulação da gestão ambiental, tanto de recursos hídricos como uso do solo, visa à recuperação de bacias hidrográficas, utilizando-se do estabelecimento de incentivos financeiros (ANA, 2008). Estes incentivos podem ser estabelecidos pelos Pagamento por de Serviços Ambientais (PSA).

A ANA, em parceria com outras instituições, vem desenvolvendo o PPA, como um instrumento para a melhoria, recuperação e proteção de recursos hídricos em bacias hidrográficas estratégicas. Esse programa é fundamentado em ações executadas no meio rural voltadas à redução da erosão e do assoreamento de mananciais, as quais proporcionem aumento da qualidade e regularidade da oferta de água (ANA, 2008). O PPA utiliza o PSA como instrumento de incentivo aos proprietários rurais de forma voluntária nas práticas voltadas a conservação da água e solo. 
No Brasil, a implantação da política pública sobre PSA tornou-se mais relevante com a Lei de Proteção da Vegetação Nativa (Lei n 12.651/2012), que autorizou o poder público federal a instituir programas de PSA como forma de incentivo e apoio à conservação dos ecossistemas, entretanto até o presente momento a lei não foi regulamentada. A expansão do PSA no Brasil tem gerado inúmeras políticas desta natureza nos âmbitos regionais e locais (PSA, 2017). Várias experiências utilizam o conceito de PSA, para manter a qualidade e quantidade dos recursos hídricos, entre eles podemos citar, o projeto Conservador das Águas de Extrema/MG, pioneiro no país, o Programa Ecocrédito em Montes Claro/MG, o Projeto Oásis nos Mananciais da Região metropolitana de São Paulo, entre outros (ANA, 2012).

A Fundação Grupo Boticário, em 2006 lançou o programa Oásis, uma iniciativa de PSA ligado à biodiversidade e à água. Até o ano de 2016, os principais resultados foram: 7 programas de PSA estruturados, 19 parcerias formalizadas; 50 processos para construção de políticas públicas de PSA; 28 normas legais de PSA elaboradas e sancionadas, cinco mil hectares em áreas naturais sob contrato de PSA, mais de 500 propriedades contratadas e cerca de 8 milhões de pessoas beneficiadas indiretamente (FIDALGO et al., 2017).

Nos últimos 15 anos, muitas experiências que utilizam o conceito de PSA tem sido implantada no país. Segundo Prado et al. (2015), após o início do projeto em Extrema (MG), 52 projetos de PSA foram identificados. No Estado de Santa Catarina, o Programa Estadual de Pagamento por Serviços Ambientais (PEPSA) implementou o pagamento das atividades humanas de preservação e melhoria dos ecossistemas que geram serviços ambientais. O Comitê Gestor do PEPSA é o responsável por coordenar os seguintes serviços ambientais: conservação dos solos, água e biodiversidade; preservação da beleza cênica; recomposição ou restauração de áreas degradadas com espécies nativas, florestais ou não; e atividades de uso sustentável, priorizando áreas sob maior risco ambiental (SANTOS et al., 2012). No estado, três projetos estão em andamento: Programa de Gestão Ambiental da Região dos Mananciais - SOS Nascentes, município de Joinville; Consórcio Municipal Quiriri, municípios de São Bento do Sul, Rio Negrinho, Corupá e Campo Alegre e o projeto Produtor de Água (PA) na Bacia Hidrográfica do Rio Camboriú (BHRC), municípios de Balneário Camboriú e Camboriú (MMA, 2011).

Inspirada pelo PPA idealizado pela ANA e por experiências internacionais, foi criado em 2009 o projeto Produtor de Água (PA) na BHRC, com o objetivo de garantir a conservação dos recursos hídricos na bacia, incentivando proprietários rurais a adotarem práticas conservacionistas em suas propriedades (SANTOS et al., 2017). Essas práticas envolvem a recuperação de áreas degradadas, a conservação dos remanescentes florestais nativos, o manejo adequado do solo e a conservação de estradas rurais com o objetivo de aumentar a qualidade e quantidade de água na BHRC.

O MMA compreende que o monitoramento é necessário para estabelecer a credibilidade dos projetos PSA, pois estes são incipientes e nem sempre cumprem com os objetivos propostos (MMA, 2011). Ao mesmo tempo, é necessário estabelecer indicadores de eficácia para os programas Produtores de Água, possibilitando subsidiar a implantação desta estratégia de conservação em diferentes bacias hidrográficas brasileiras. Desta forma, estudos para definir indicadores de conformidade entre programas e projetos, bem como medir a percepção e aderência dos proprietários contratados são fundamentais para garantir o sucesso 
de projetos Produtores de Água.

\section{MATERIAIS E MÉTODOS}

\section{Área de estudo}

A BHRC drena uma área de aproximadamente $200 \mathrm{Km}^{2}$. O rio principal, o Rio Camboriú, possui cerca de $40 \mathrm{~km}$ de extensão e banha os municípios de Balneário Camboriú e Camboriú (Figura 1). Cerca de 90\% das nascentes que compõem a bacia do Rio Camboriú se encontram no município de Camboriú (ANTUNES et al., 2007). O relevo da bacia é caracterizado por duas unidades: a Serra do Tabuleiro e Planícies Litorâneas. A Serra do Tabuleiro distinguisse por encostas íngremes e vales profundos com depósitos sedimentares de sílico-argiloso e areia de quartzos, com suas características peculiares, favorecendo assim o processo de erosão em áreas desmatadas, bem como deslizamento (URBAN, 2008). 0 presente estudo foi realizado na área de intervenção do projeto $\mathrm{PA}$, localizada à montante da BHRC, com aproximadamente $138 \mathrm{~km}^{2}(\mathrm{DACOL}$, 2011) que corresponde a cerca de $70 \%$ da área de toda da bacia (Figura 1).

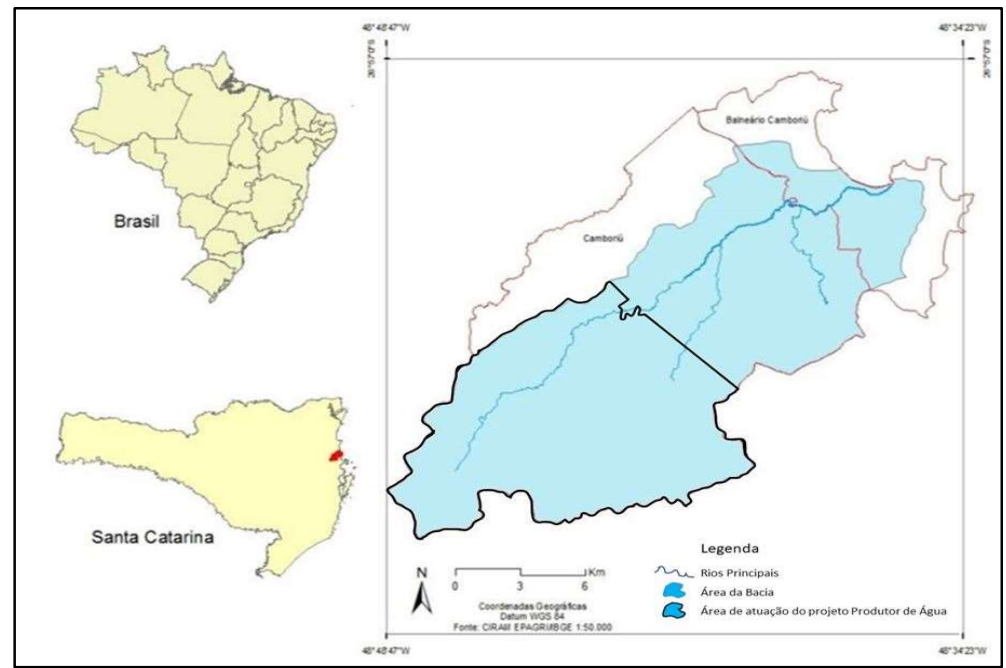

Figura 1: Localização do Projeto Produtor de Água da Bacia Hidrográfica do Rio Camboriú (SC). Fonte: modificado de Yokoyama (2003).

\section{Procedimentos metodológicos}

Para a análise de conformidade foi feito um diagnóstico identificando o nível de consonância entre o projeto Produtor de Água (PA) e o Programa Produtor de Água (PPA) da ANA. O nível de conformidade analisou os seguintes aspectos: justificativa, descrição, objetivo geral, objetivo específicos e metas. Para cada aspecto foi atribuído um valor percentual do nível de conformidade, variando entre excelente (supera as expectativas; $>100 \%$ ) e ruim $(<25 \%)$. O cálculo para determinar o nível de conformidade foi definido pela equação: Conformidade $=\left\{\left[\left(n^{\circ}\right.\right.\right.$ de notas $\left.10 \times 10\right)+\left(n^{\circ}\right.$ de notas $\left.8 \times 8\right)+\left(n^{\circ}\right.$ de notas $\left.6 \times 6\right)+\left(n^{\circ}\right.$ de notas $\left.4 \times 4\right)+$ $\left(n^{\circ}\right.$ de notas $\left.\left.1 \times 1\right)\right] \div\left(n^{\circ}\right.$ de variáveis $-n^{\circ}$ de variáveis que não se aplica) $\}$.

Com relação a percepção dos proprietários rurais sobre o projeto PA foi aplicado questionário, avaliando o nível de satisfação dos mesmos. As questões foram elaboradas visando identificar, reconhecer e mensurar como o proprietário rural percebe o projeto PA. No questionário foram contemplados os aspectos: 
receptividade, engajamento e benefícios, como elementos indicadores de sucesso do projeto

As perguntas $(n=9)$ incluídas no questionário foram: Como você conheceu o projeto PA? Há quanto meses sua propriedade faz parte do projeto PA? Você como proprietário recebeu recursos da Concedente para desenvolver sua parte no projeto? De quanto em quanto tempo recebe acompanhamento técnico por parte da Concedente? Você considera o projeto PA receptivo quando procurado? Qual seu grau de envolvimento com o projeto PA? Quais os benefícios que o projeto proporciona para você e sua família? O valor financeiro pago pela Concedente está de acordo com suas expectativas? Em sua opinião o projeto PA está contribuindo para melhoria da água na bacia do Rio Camboriú? Você aconselharia outro proprietário rural a participar do projeto PA?.

\section{RESULTADOS E DISCUSSÃO}

\section{Nível de conformidade}

O Programa Produtor de Água (PPA) da ANA foi criado em 2001 como instrumento voltado para melhoria, proteção e recuperação dos recursos hídricos estratégicos e o projeto Produtor de Água (PA) da BHRC foi criado em 2009, com o intuito de aumentar a disponibilidade de água na bacia. Em relação a justificativa, o PPA aborda os tópicos: erosão hídrica como principal causa da degradação do solo e dos recursos hídricos; desrespeito às leis ambientais; uso incorreto do solo que aceleram o processo de erosão; e incentivo a adoção de práticas conservacionistas para proteção do solo e dos recursos hídricos. No caso do PA, foram identificadas: atividades de rizicultura, pecuária, carvoaria e agrícolas como as principais responsáveis pela degradação de áreas sensíveis; desiquilibro do balanço hídrico com consumo elevado de água nos períodos mais quentes e o cultivo de arroz; e incentivos financeiros para áreas conservadas e restauradas. Assim, o projeto PA não inclui o desrespeito às leis ambientais, resultando em um nível de conformidade de $75 \%$, o que corresponde a nota 8 nos critérios de pontuação estabelecidos (Tabela 1).

Tabela 1: Critérios e pontuação para análise de conformidade do projeto Produtor de Água na Bacia Hidrográfica do Rio Camboriú.

\begin{tabular}{|c|c|c|c|c|c|}
\hline Categorias & Excelente & Ótima & Boa & Regular & Ruim \\
\hline Nota & 10 & 8 & 6 & 4 & 1 \\
\hline $\begin{array}{l}\text { Descrição } \\
\text { Variável }\end{array}$ & supera as expectativas & 100 a $75 \%$ & 74 a $50 \%$ & 49 a $25 \%$ & $<25 \%$ \\
\hline \multicolumn{6}{|l|}{ Justificativa } \\
\hline \multicolumn{6}{|l|}{ Descrição } \\
\hline \multicolumn{6}{|l|}{ Objetivo Geral } \\
\hline \multicolumn{6}{|l|}{ Objetivo Específico } \\
\hline Meta & Não se aplica & & & & \\
\hline
\end{tabular}

Na variável descrição, o PPA descreve como sendo um Instrumento pelo qual a União apoia a melhoria, recuperação e proteção de recursos hídricos em bacias hidrográficas estratégicas através da política PSA. Por outro lado, o PA promove a recuperação ambiental da bacia, propondo incentivos financeiros aos proprietários rurais que aderem, sendo as principais ações: recuperar e conservar áreas mais sensíveis. Neste caso, o projeto PA aborda na totalidade os itens do PPA, representando $100 \%$ de conformidade (nota 8) (Tabela 1). 
Para a variável objetivo geral, o PPA considera o seguinte: apoiar projetos de pagamento por serviços ambientais de proteção hídrica que visem promover a melhoria da qualidade; ampliação da oferta das águas; e regularização da vazão dos corpos hídricos. O objetivo geral do PA busca desenvolver instrumentos, estratégias e métodos para conservar e restaurar matas ciliares e áreas sensíveis para promover qualidade, quantidade e regulação do fluxo de água no âmbito da BHRC e incentivar financeiramente os proprietários rurais que aderirem ao projeto, a fim de proteger os mananciais e adequar as propriedades rurais à legislação ambiental. A análise do nível de conformidade mostra que o PA supera o PPA, pois aborda a metodologia a ser aplicada, superando as expectativas (nota 10) (Tabela 1).

Nos objetivos específicos os PPA destaca que é preciso estimular o desenvolvimento das políticas de PSA de proteção hídrica no Brasil; apoiar projetos em áreas de mananciais de abastecimento público com conflito de usos de recursos hídricos, problemas de baixa qualidade das águas, vazões e regimes de rios sensivelmente alterados, eventos hidrológicos críticos; difundir o conceito de manejo integrado do solo, da água e da vegetação; e garantir a sustentabilidade socioeconômica e ambiental dos manejos e práticas implantadas, por meio de incentivos, inclusive financeiros, aos agentes selecionados. Para os objetivos específicos no projeto PA é necessário: garantir a sustentabilidade socioeconômica e ambiental das atividades desenvolvidas na bacia, por meio de incentivos financeiros aos proprietários rurais; aumentar o grau de proteção das áreas conservadas e recuperar áreas degradadas; reduzir a erosão e o assoreamento; apoiar a correta manutenção das estradas vicinais; contribuir para a regularização hídrica da bacia e desenvolver ações de Educação Ambiental para a comunidade local, informando sobre a importância de preservar e recuperar as áreas ripárias. Com relação aos objetivos específicos, o projeto PA relaciona uma informação que o PPA não abrange, a questão da Educação Ambiental, assim, superando as expectativas (nota 10) (Tabela 1).

Para a variável meta o PPA estabelece: divulgação do programa e da política de PSA de proteção hídrica em todas as unidades da federação; manutenção da página do Programa na página eletrônica da ANA; incentivo a projetos em todas as regiões do Brasil; treinamento de potenciais agentes executores de projetos (Estados, municípios, comitês de bacias, cooperativas, etc.) e estímulo à formação de arranjos organizacionais. O PA tem como metas: adesão de pelo menos $40 \%$ dos proprietários rurais por microbacia; 500hectares de áreas degradadas em processo de restauração priorizando as matas ciliares; 5200hectares de áreas conservadas protegidas pelos proprietários por contrato com a Concedente; $180 \mathrm{~km}$ de estradas vicinais adequadamente conservadas; implantação de plano de monitoramento hidrológico da bacia e implantação de programa de educação ambiental na bacia. Na variável meta, foi atribuído 'não se aplica', pois, a variável apresenta relação indireta entre PPA e projeto PA, pois são independentes. Assim, não foi dada nota na análise de conformidade para a variável meta.

A análise da conformidade apresentou nota final de 90\%, o que demostra uma ótima relação entre o PPA e projeto PA. Nesta avaliação, deve ser considerado que o PPA foi desenvolvido com aspecto mais amplo, podendo ser adaptado em várias bacias hidrográficas. Apesar do projeto PA da BHRC apresentar conformidade elevada com o PPA, este também apresenta singularidades. Segundo Atkinson et al. (2006) 
existe uma tendência de realizar projetos dentro de programas, requerendo a criação de organizações temporárias e flexíveis para seu gerenciamento. Patah et al. (2009) observaram que é cada vez mais frequente a utilização de projetos na execução de serviços. Bartlett (2006) argumenta que projetos inseridos dentro programa não tem que estar relacionados na sua totalidade, entretanto a conformidade entre ambos pode contribuir para a obtenção de objetivos e estratégias comuns.

\section{Percepção dos proprietários rurais}

Avaliar a percepção dos proprietários rurais que aderem aos projetos PA é de suma importância para o desenvolvimento do mesmo, pois são os principais atores do projeto. Assim, considerando que a percepção é parte do processo de formação de conhecimentos (MARINS, 2008), esta pode ser utilizada como um indicador do sucesso de projetos PA. A percepção através do uso da memória das pessoas pode desmontar riqueza e diversidade não conhecidas, e que podem contribuir com a história de ambiente ou projetos (RABELO et al., 2019). O questionário aplicado aos proprietários rurais através de entrevista pessoal, representou $53 \%$ do total dos contratantes do projeto. As demais formas de aplicação dos questionários foram e-mail (18\%), telefone (12\%) e vistorias (18\%), sendo possível nesta última conhecer in situ as propriedades e proprietários.

Em relação a percepção dos proprietários sobre o projeto PA, a maioria destes tiveram acesso a informações do projeto através de conhecidos $(35,7 \%)$ ou pela Concedente $(31,3 \%)$. A televisão foi o terceiro meio usado pelos proprietários (12,5\%). Comitê Camboriú, universidade e folder tiveram uma participação menor, enquanto os meios de comunicação internet e rádio não foram utilizados (Figura 2-A). Esse resultado mostra que o contato pessoal ainda é um instrumento-chave para o sucesso de ações no meio rural.

O projeto PA teve a adesão de 19 proprietários no período de 05/03/2013 a 28/07/2017, sendo que dois não permaneceram no projeto. Propriedades com mais de 18 meses no projeto correspondem a 75,0\% (Figura 2-B), de 12 a 18 meses representam 18,8\%, e de 0 a 12 meses somam 12,6\%. Uma área sem cobertura de vegetação nativa ao ser restaurada necessita de recursos financeiros para aquisição: de mudas, serviços de manutenção e cercamento da área para que animais não danifiquem as mudas e o solo, neste caso o aporte dos recursos financeiros é realizado pela Concedente. Propriedades que receberam os recursos financeiros de forma indireta para a restauração representam $37,5 \%$, enquanto $50,0 \%$ não receberam recursos por se tratar de área conservadas (Figura 2-C).

As vistorias do projeto PA são semestrais, o que explica o fato de $76,5 \%$ dos entrevistados responderam que o acompanhamento é realizado semestralmente e $23,5 \%$ responderam que recebem acompanhamento trimestral (Figura 2-D). Em caso de restauração, as propriedades necessitam de acompanhamento técnico com maior frequência. O contato mais frequente dos proprietários com os gestores do projeto PA é realizado através da Concedente e equipe de vistorias, designada pelo Grupo Gestor (GG) (SANTOS et al., 2017). A preocupação dos gestores em dar a devida atenção aos proprietários foi observada por $100 \%$ dos proprietários, que classificaram a receptividade acima de bom (Figura 2-E). 

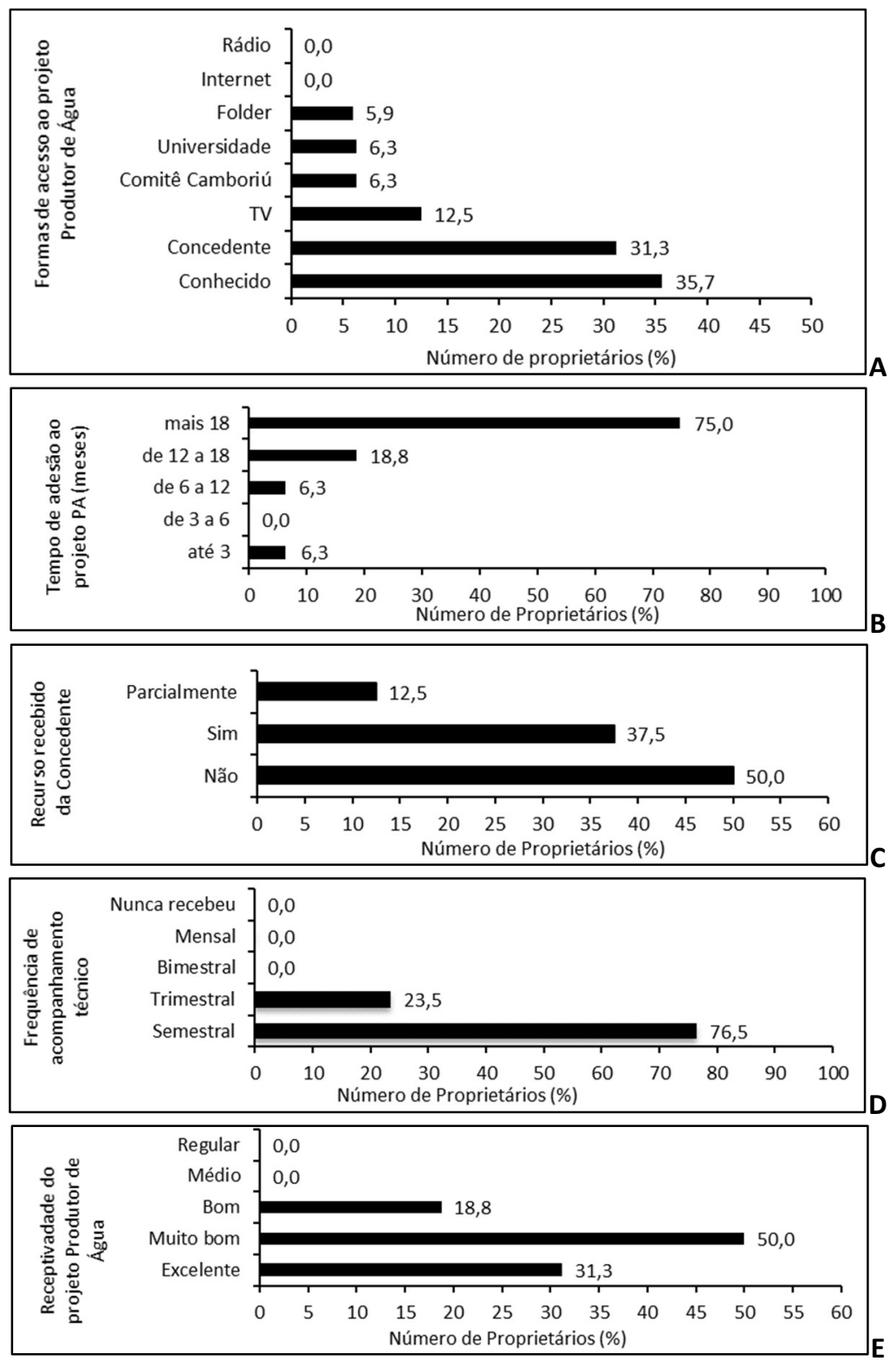

Figura 2: Formas de acesso ao projeto Produtor de Água pelos proprietários rurais (A), tempo das propriedades rurais no projeto (B), percentual de acesso aos recursos da Concedente para o desenvolvimento do projeto Produtor de Água (C), frequência de acompanhamento técnico por parte do Grupo Gestor (D), receptividade do projeto Produtor de Água junto aos proprietários rurais (E), na Bacia Hidrográfica do Rio Camboriú (SC).

Uma vez que se estabelece o contrato entre a Concedente e os Proprietários Rurais, estes têm se dedicado na conservação e proteção das áreas conservadas ou restauradas. O registro de $100 \%$ de envolvimento dos proprietários acima de bom (Figura 3-A), reflete o engajamento dos proprietários rurais com o projeto PA. Esse fato foi observado durante as vistorias in loco e registrados nos Relatórios de Vistoria. Durante as vistorias, os proprietários têm interesse de mostrar as áreas conservadas e em estágio de recuperação. Em situações que fogem ao seu controle, exemplo do roubo de palmito e caça ilegal, os proprietários rurais informam a equipe de vistoria, demostrando engajamento com o projeto PA.

Com relação aos benefícios proporcionados pelo projeto PA, o entrevistado podia eleger mais de uma opção. As respostas que mais se destacaram foram o incentivo ambiental ( $75,5 \%)$ e o financeiro $(52,9 \%)$. O valor financeiro para alguns proprietários rurais, dependendo da área no projeto PA é pequeno, mas a satisfação de estar participando do mesmo faz sentir-se bem, representando os benefícios pessoal e social 
que alcançam 47,1\% cada (Figura 3-B).

O PSA é o principal benefício que o projeto PA proporciona aos proprietários rurais. Um total de 58,8\% dos proprietários estão satisfeitos com o PSA, e o restante não (Figura 3-C). Os valores estabelecidos para o PSA foram definidos em 2012 e, deste então, não passaram por revisão, portanto, o valor pago pode estar defasado em termos de mercado, apesar de ser atualizado anualmente pela Unidade Fiscal Municipal de Balneário Camboriú.

Durante a aplicação do questionário três proprietários manifestaram que têm percebido aumento da quantidade de água na bacia e atribuem este aumento ao projeto PA. Um total de $66,7 \%$ dos proprietários pensam que o projeto PA contribui para a melhoria da qualidade da água, enquanto que 33,3\% pensam que não ou que contribui parcialmente (Figura 3-D).

A participação de proprietários no projeto PA ainda é pequena, representando apenas 5,7\%, de um total de 298 propriedades da BHRC. Assim a divulgação do projeto PA é importante para ampliar o mesmo, sendo que reuniões semestrais na BHRC seriam importantes para difundir o projeto (SANTOS et al., 2018). A manifestação dos proprietários, nestas reuniões semestrais, que já aderiam ao projeto seria um incentivo para outros proprietários rurais. Com o resultado de 94,4\% aconselhando outros proprietários a participar do projeto (Figura 3-E), fica evidenciado o elevado grau de engajamento dos mesmos com o PA.
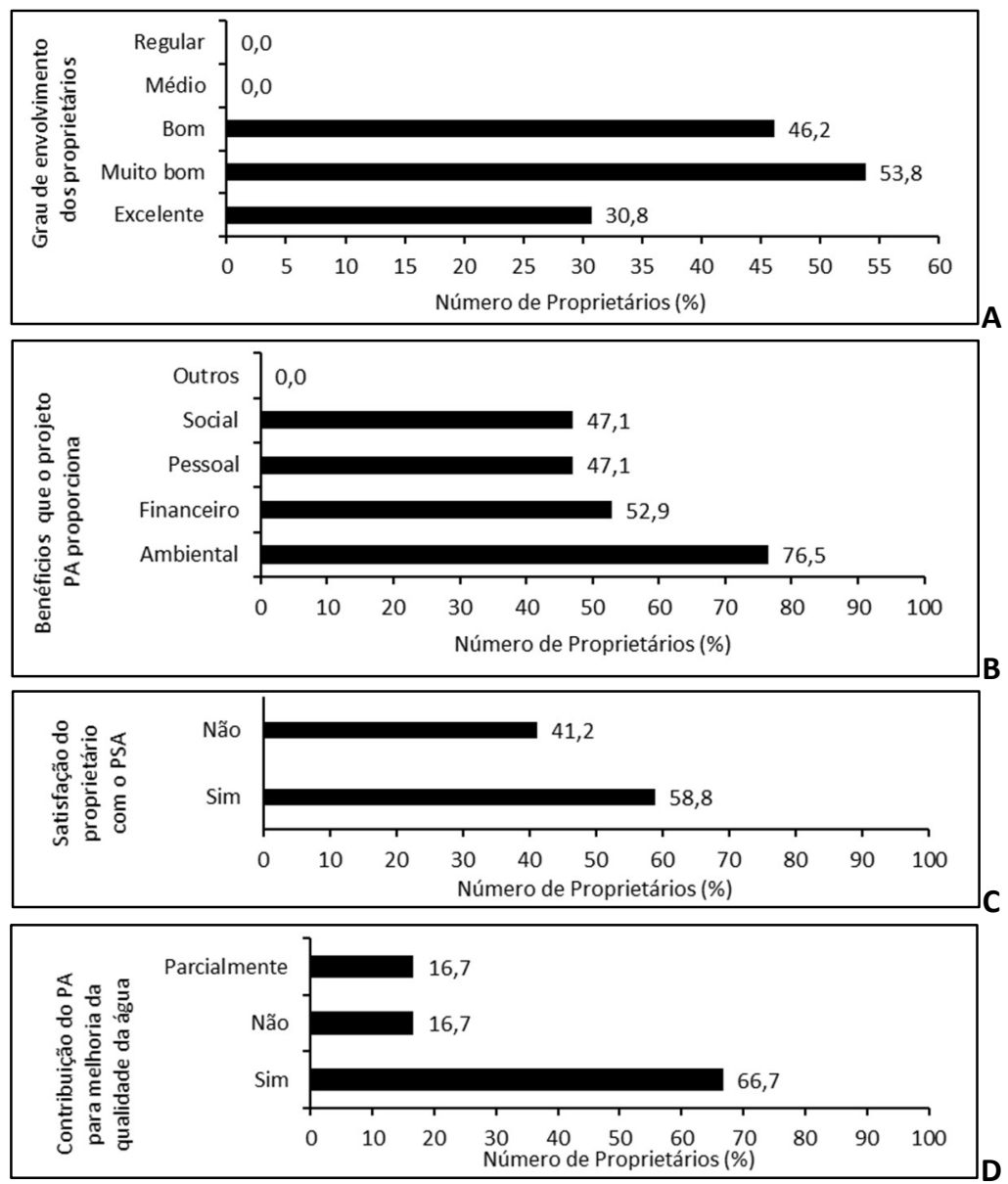


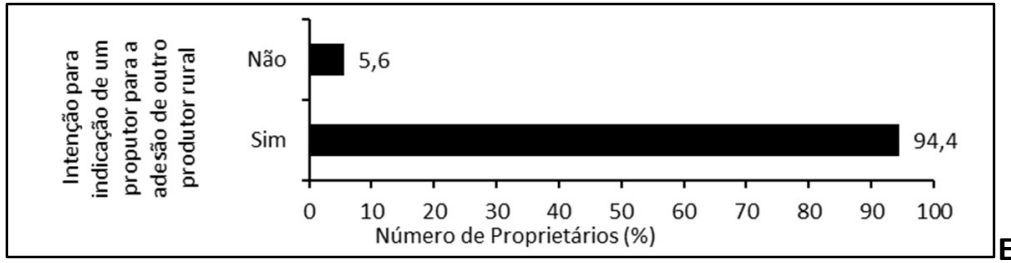

Figura 3: Grau de envolvimento do proprietário rural no projeto Produtor de Água (A), benefícios que o projeto Produtor de Água proporciona ao produtor rural e família (B), satisfação dos produtores rurais em relação ao valor do Pagamento por Serviços Ambientais (C), contribuição do projeto na melhoria da qualidade da água (D), intenção para indicar outros produtores para aderir ao projeto Produtor de Água (E), na Bacia Hidrográfica do Rio Camboriú (SC).

\section{CONCLUSÕES}

O projeto PA na BHRC está sendo divulgado através de conhecidos e pela própria Concedente. A adesão dos proprietários, por ser voluntária, favorece a permanência de proprietários rurais no projeto PA, que é superior a 18 meses. Os produtores rurais acreditam que o projeto está contribuindo para o aumento da qualidade e quantidade de água na BHRC. A Concedente e o Grupo Gestor buscam a excelência no atendimento aos proprietários e realizam os repasses de recursos para a execução do projeto PA nas propriedades, isso resulta em que a maior parte dos proprietários estão satisfeito com o valor pago pelos serviços ambientais e aconselham outros produtores a participarem do projeto.

Desta forma, foi evidenciado que o grau de engajamento dos proprietários rurais reflete a confiança que os mesmos demostram ter em relação ao projeto, percebendo ser uma das soluções para preservar o ecossistema. A partir dos resultados da análise de conformidade e percepção dos proprietários rurais, verifica-se que o Projeto Produtor de Água da BHRC estabeleceu bons níveis qualidade, podendo ser referência na gestão de outros projetos Produtores de Água em andamento ou em implantação no Brasil.

AGRADECIMENTOS: a Coordenação de Aperfeiçoamento de Pessoal de Nível Superior (CAPES) pela concessão de bolsa de mestrado.

\section{REFERÊNCIAS}

ANA. Agência Nacional de Águas. Manual Operativo: Programa Produtor de Água. Brasília: ANA, 2012.

ANA. Agência Nacional de Águas. Programa Produtor de Água. Brasília: ANA, 2008.

ANTUNES, A.; SCHWINGEL, P. R.; BURLIGA, A. L. M.; URBAN, S.. Composição do fito plâncton da BHRC (SC, Brasil) durante o verão de 2005. Braz. J. Aquat. Sci. Technol., v.11, n.2, p.33-43, 2007. DOI:

http://dx.doi.org/10.14210/bjast.v11n2.p33-43

ATKINSON, R.; CRAWFORD, L.; WARD, S.. Fundamental Uncertainties in Projects and the Scope of Project Management. International Journal of Project Management, v.24, n.8, p.687-698, 2006. DOI: http://dx.doi.org/10.1016/j.ijproman.2006.09.011

BARBOSA, V.. A Última Gota. São Paulo: Planeta do Brasil, 2015.
BARTLETT, J.. Managing Programmes of Business Change. 4 ed. Hampshire: Project Manager Today, 2006.

BICUDO, C. E. M.; TUNDISI, J. G.; SCHEUENSTUHL, M. C. B.. Águas do Brasil. São Paulo: Instituto de Botânica, 2010.

BRASIL. Lei de Criação da Agência Nacional de Água. Brasília: DOU, 2000.

DACOL, K. C.. Pagamento por Serviços Ambientais: Critérios de Valoração do Projeto Produtor de Água do Rio. Monografia (Graduação) - Pontifícia Universidade Católica do Paraná, Curitiba, 2011.

FIDALGO, E. C. C.; PRADO, R. B. P.; TURETTA, A. P. D.; SCHULER, A. E.. Manual para Pagamento por Serviços Ambientais Hídricos. Brasília: EMPRAPA, 2017.

MARIN, A. A.. Pesquisa em Educação Ambiental e Percepção Ambiental. Rev. UFPR, v.3, n.1, p.203-222, 2008. 
MMA. Ministério do Meio Ambiente. Pagamentos por Serviços Ambientais na Mata Atlântica: lições aprendidas e desafios. Brasília: MMA, 2011.

MMA. Ministério do Meio Ambiente. Mata Atlântica: Manual de Adequação. Brasília: MMA, 2010.

PATAH, L. A.; CARVALHO, M. M.. Alinhamento entre estrutura organizacional de projetos e estratégia de manufatura: uma análise comparativa de múltiplos casos. Gestão \& Produção, v.16 n.2, p.301-312, 2009. DOI: http://dx.doi.org/10.1590/S0104-530X2009000200012

PSA. Pagamento por Serviços Ambientais. Guia para a formulação de políticas públicas estatuais e municipais de pagamento por serviços ambientais. PSA, 2017.

RABELO, L.; SCWINGEL, R. P.. Resgate histórico como instrumento de avaliação da degradação ambiental em bacia hidrográfica costeira. Geosul, v.34, n.73. p.238-261, 2019. DOI: https://doi.org/10.5007/1982-5153.2019v34n73p238

SANTOS, P.; BRITO, B.; GUARANY, O.; MASCHIETTO, F.; MONZONI, M.. Marco Regulatório sobre Pagamento por Serviços Ambientais no Brasil. Belém: IMAZON, 2012.
SANTOS, P. H.; SCHWINGEL, P. R.. Programa de educação ambiental para projetos Produtores de Água: estudo de caso da bacia Hidrográfica do Rio Camboriú/SC, Brasil. Braz. J. Aquat. Sci. Technol., v.22, n.1. p.1-4, 2018. DOI: http://dx.doi.org/10.14210/bjast.v22n1.13262

SANTOS, P. H.; SCHWINGEL, P. R.. Proposta para procedimentos de vistoria de Projetos Produtor de Água: Bacia Hidrográfica do Rio Camboriú (SC), Brasil. Braz. J. Aquat. Sci. Technol., v.21, n.1. p.1-3, 2017. DOI: http://dx.doi.org/10.14210/bjast.v21n1.12367

URBAN, S. R.. Uso do Solo na Bacia Hidrográfica do Rio Camboriú (SC) e sua Influência sobre a Qualidade da Água. Dissertação (Mestrado) - Universidade do Vale Itajaí, Blumenau, 2008

TUNDISI, J. G.; TUNDISI, T. M.. Limnologia. São Paulo: Oficina de Textos, 2008

YOKOYAMA, M. M.. Desenvolvimento de uma proposta para Recuperação de duas áreas degradadas da Bacia hidrográfica do Rio Camboriú (SC). Monografia (Engenharia Ambiental) - Universidade do Vale do Itajaí, Blumenau, 2003.

A CBPC - Companhia Brasileira de Produção Científica (CNPJ: 11.221.422/0001-03) detém os direitos materiais desta publicação. Os direitos referem-se à publicação do trabalho em qualquer parte do mundo, incluindo os direitos às renovaç̃oes, expansões e disseminações da contribuiç̃o, bem como outros direitos subsidiários. Todos os trabalhos publicados eletronicamente poderão posteriormente ser publicados em coletâneas impressas sob coordenação da Sustenere Publishing, da Companhia Brasileira de Produção Científica e seus parceiros autorizados. Os (as) autores (as) preservam os direitos autorais, mas não têm permissão para a publicação da contribuição em outro meio, impresso ou digital, em português ou em tradução. 